\title{
OUTCOMES OF LAPAROSCOPIC CHOLECYSTECTOMY IN DIFFERENT GRADES OF GALL BLADDER INFLAMMATION A TERTIARY CARE CENTRE EXPERIENCE
}

\author{
Amir Ali, Mukarram Hussain Syed*, Taimoor Ashraf**, Farheen Aslam***, Gufran Ahmad****, Afnan Akbar*** \\ Combined Military Hospital Chhor/National University of Medical Sciences (NUMS) Pakistan, *Combined Military Hospital Peshawar/National University of \\ Medical Sciences (NUMS) Pakistan, ${ }^{* *}$ Frontier Corps, Balouchistan Pakistan, ${ }^{* * *}$ Combined Military Hospital/National University of Medical Sciences (NUMS) \\ Rawalpindi Pakistan, ${ }^{* * * *}$ Frontier Corps, Khyber Pakhtunkhwa Pakistan
}

\begin{abstract}
Objective: To find the outcomes of laparoscopic cholecystectomy in gall bladders with all grades peri-operative inflammation. Study Design: Prospective observational study.

Place and Duration of Study: Combined Military Hospital, Rawalpindi, from Nov 2018 to Aug 2019. Methodology: All patients with symptomatic gall bladder disease who underwent laparoscopic cholecystectomy (emergency/ elective procedure) and American Anesthesiology Society (ASA) Score 1 or 2 were included in the study.

Results: A total of 330 patients with a mean \pm SD age of $48.01 \pm 14.13$ years underwent laparoscopic cholecystectomy. Out of 330 patients, $129(39.1 \%)$ had acute inflammation of gall bladder while $201(69.9 \%)$ cases were operated electively. The rate of conversion and complications were somehow lesser in both categories as the overall conversion rate was 15 (4.5\%).

Conclusion: Laparoscopic cholecystectomy is the gold standard treatment for symptomatic gall stones. Moreover, it is safe option in acute and chronic inflammation of Gall bladder if performed by a experienced laparoscopic surgeon.
\end{abstract}

Keywords: Cholecystectomy, Grades, Inflammation, Laparoscopy.

This is an Open Access article distributed under the terms of the Creative Commons Attribution License (https://creativecommons.org/licenses/by-nc/4.0/), which permits unrestricted use, distribution, and reproduction in any medium, provided the original work is properly cited.

\section{INTRODUCTION}

Laparoscopic cholecystectomy evolved as the most acceptable management option for symptomatic gall bladder disease. Since its introduction in 1990s, there has been a huge paradigm shift in the management of the disease both electively and in emergency surgery. Worldwide, cholecystectomy is one of the most common reasons for hospital admission. Mortality associated with the disease varies according to severity of the disease and is reported to be $0.4-6 \%{ }^{1}$. The incidence of cholelithiasis varies in different ethnicities and regions of the world from $10-15 \%$ and there is $35 \%$ lifetime recurrence rate of symptoms or complications in such patients ${ }^{2}$. Laparoscopic cholecystectomy (LC) in comparison to conventional open cholecystectomy is associated with shorter post-operative stay and lower rate of intra and post-operative complications like sepsis, surgical site infection, and improved cosmetic result 3,5 . However, adopting LC as a new technique of treatment for acute and chronic cholecystitis has introduced a new spectrum of risks and complications ${ }^{6}$. A major risk associated with LC is $0.3-0.8 \%$ incidence of injury to the common bile duct ${ }^{7}$. Furthermore, there is also a greater risk of intestinal injuries, pancreatitis, injuries due to cautery in LC as compared to open cholecystectomy ${ }^{8}$. There are various techniques of LC

Correspondence: Dr Amir Ali, Classified Surgical Specialist, Combined Military Hospital, Chhor Pakistan

Received: 22 Jan 2021; revised received: 02 Aug 2021; accepted: 13 Aug 2021 like conventional and standard 4 port and single port technique. Conventional technique is still more popular in terms of outcomes ${ }^{9}$. LC has revolutionized the modern surgery to provide a safer and less time taking surgical management option for cholecystitis. There are certain predictors of surgical outcome with this technique which should not be ignored at all. A thorough pre and intra-operative evaluation of the patient in terms of grading of inflammation of gall bladder is one of the pivotal steps regarding the positive outcome in this management option ${ }^{10}$.

The objective of study was to find the outcomes of laparoscopic cholecystectomy in gall bladders with all grades peri-operative inflammation.

\section{METHODOLOGY}

It was a prospective observational study carried out in department of General Surgery of Combined Military Hospital Rawalpindi, from November 2018 to August 2019. A written informed consent was taken from all the participants. Protocol of the study was approved by institutional review board (IRB \# 129/12/ 20). Non-probability consecutive sampling technique was used. A sample size of 151 was calculated by Open Epi Software using reference population of $11 \%$ and 95\% confidence level but we included all the patients operated by laparoscopic cholecystectomy fulfilling strict inclusion/exclusion criteria ${ }^{18}$. All patients with symptomatic gall bladder disease who underwent laparoscopic cholecystectomy (emergency/elective 
procedure) and American Anesthesiology Society (ASA) score 1 or 2 were included in the study. Patients with American Anesthesiology Society (ASA) Score 3 or 4, previous history of any abdominal or laparoscopic surgery (ERCP/MRCP evidence of gall bladder adhesions), history of comorbid conditions (diabetes melitus, hypertension, liver/renal/cardiopulmonary disease and Obesity; BMI>30) and preoperative diagnosis of gall bladder carcinoma were excluded from the study. Patients' demographic details, pre-operative, per-operative and post-operative data were documented on a predesigned proforma using Microsoft Excel 360. Laparoscopic cholecystectomy was attempted in all patients with different grades of gallbladder disease. Single Laparoscopic surgeon assessed the grades of gall bladder per-operatively. Grades were categorized as grade 1; thin wall gall bladder without adhesions, grade 2; thin wall gall bladder with adhesions, grade 3; thick wall gall bladder, grade 4; thick wall gall bladder with chronic inflammation, grade 5 ; thick wall gall bladder with acute inflammation. One investigator documented all the data along with additional information including conversion and reason for conversion to open cholecystectomy during the laparoscopic cholecystectomy, duration of operation (time noted down from skin incision to skin closure) and post-operative stay (number of nights stayed at hospital) in the hospital. Additional information including length of intensive care unit stay (number of nights stayed), post- general surgery under general anaesthesia and using a 4 port standard technique. A hybrid technique was used to create the pneumoperitoneum. Indications for conversion to open cholecystectomy were Empyma GB, CBD stones, cholecystoduedenal fistula, dense adhesion at calot triangle, difficult anatomy and anamolies.

Statistical analysis was done using SPSS-23 and Microsoft excel 360. Quantitative variables were correlated using a chi-square test and the $p$-value of $\leq 0.05$ was considered statistically significant.

\section{RESULTS}

A total of 330 patients with a mean \pm SD age of $48.01 \pm 14.13$ years underwent laparoscopic cholecystectomy, including $173(52.4 \%)$ females with mean age $46.54 \pm 13.85$ and $157(47.6 \%)$ males with mean age $49.62 \pm 14.31$. Out of 330 patients, $129(39.1 \%)$ had acute inflammation of gal bladder while $201(60.9 \%)$ cases were operated electively, they had no active inflammation of gall bladder on ultrasonography. The rate of conversion and complications were somehow lesser in both categories as the overall conversion rate was 15 $(4.5 \%)$ and details are given in table-I.

In the sample, $4(1.2 \%)$ of the patients had grade 1 inflammation, $177(53.6 \%)$ had grade $2,66(20 \%)$ grade $3,20(6.1 \%)$ grade 4 , and $63(19.1 \%)$ grade 5 . Post operative complications are tabulated in table-II.

Association of gender with the grades of inflam-

Table-I: Grades of inflammation of gall bladder vs indications for conversion to open cholecystectomy.

\begin{tabular}{|c|c|c|c|c|c|c|c|}
\hline $\begin{array}{l}\text { Indication for } \\
\text { Conversion to Open } \\
\text { Cholecystectomy }\end{array}$ & Number (Percentage) & $\begin{array}{l}\text { Grade } 1 \\
4(1.2 \%)\end{array}$ & $\begin{array}{c}\text { Grade } 2 \\
177 \\
(53.6 \%) \\
\end{array}$ & $\begin{array}{l}\text { Grade } 3 \\
66(20 \%)\end{array}$ & $\begin{array}{c}\text { Grade } 4 \\
20(6.1 \%)\end{array}$ & $\begin{array}{c}\text { Grade } 5 \\
63 \\
(19.1 \%) \\
\end{array}$ & $\begin{array}{c}p- \\
\text { value }\end{array}$ \\
\hline Empyema & $\begin{array}{c}6(1.8 \%) \\
\text { (Acute Cholecystitis } \\
\text { n=4, Chronic } \\
\text { Cholecystitis; } n=2) \\
\end{array}$ & - & $2(0.6 \%)$ & $1(0.3 \%)$ & $1(0.3 \%)$ & $2(0.6 \%)$ & 0.029 \\
\hline $\begin{array}{l}\text { Common Bile Duct } \\
\text { Stone }\end{array}$ & $\begin{array}{c}6(1.8 \%) \\
\text { (Acute Cholecystitis } \\
\text { n=0, Chronic } \\
\text { Cholecystitis; } n=6)\end{array}$ & - & $3(0.9 \%)$ & $1(0.3 \%)$ & - & $2(0.6 \%)$ & 0.017 \\
\hline Biliary pancreatitis & $\begin{array}{c}3(0.9 \%) \\
\text { (Acute Cholecystitis } \\
n=0, \text { Chronic } \\
\text { Cholecystitis; } n=3 \text { ) }\end{array}$ & - & - & $1(0.3 \%)$ & $1(0.3 \%)$ & $1(0.3 \%)$ & 0.06 \\
\hline
\end{tabular}

operative complications, cholelithiasis with number of stones, thickness of gall-bladder wall, Ultrasonography abdomen findings were also documented. Laparoscopic cholecystectomy was performed by a team of laparoscopic surgeons comprising a senior professor of surgery, a laparoscopic surgeon and a fourth year resident mation are given in table-III. The provisional diagnoses made upon ultrasounds with were; acute cholecystitis $10(3 \%)$, biliary pancreatitis $3(0.9 \%)$, common bile duct stone $6(1.8 \%)$, contracted gall bladder $7(2.1 \%)$, dilated gall bladder 5 (1.5\%), empyema gall bladder $6(1.8 \%)$, multiple gall stones $272(82.4 \%)$, omental adhesions 2 
$(0.6 \%)$, omentum perforations $1(0.3 \%)$, para-umblical hernia $2(0.6 \%)$ and solitary stones in $12(3.6 \%)$. who underwent open cholecystectomy initially, supporting LC as the gold standard treatment option ${ }^{16}$.

Table-II: Grades of inflammation of gall bladder vs post-operative complications.

\begin{tabular}{|c|c|c|c|c|c|c|}
\hline Complications & $\begin{array}{l}\text { Grade } 1 \\
4(1.2 \%)\end{array}$ & $\begin{array}{r}\text { Grade } 1 \\
4(1.2 \%) \\
\end{array}$ & $\begin{array}{c}\text { Grade } 2 \\
177(53.6 \%)\end{array}$ & $\begin{array}{l}\text { Grade } 3 \\
66(20 \%) \\
\end{array}$ & $\begin{array}{c}\text { Grade } 4 \\
20(6.1 \%) \\
\end{array}$ & $p$-value \\
\hline Common hepatic duct injury & - & $2(0.6 \%)$ & - & - & - & \multirow{9}{*}{0.023} \\
\hline Bile leak & - & - & - & $1(0.3 \%)$ & - & \\
\hline Pancreatitis & - & - & $1(0.3 \%)$ & - & $2(0.6 \%)$ & \\
\hline Ileus & - & - & $1(0.3 \%)$ & - & - & \\
\hline Surgical Site infection & - & $2(0.6 \%)$ & $1(0.3 \%)$ & - & - & \\
\hline Pneumonia & - & $1(0.3 \%)$ & - & - & - & \\
\hline Atelectasis & - & - & - & $1(0.3 \%)$ & - & \\
\hline Deep vein thrombosis & - & - & - & - & $1(0.3 \%)$ & \\
\hline Sepsis & - & - & - & $1(0.3 \%)$ & $1(0.3 \%)$ & \\
\hline
\end{tabular}

\begin{tabular}{l|c|c|c|c|c|c|c}
\hline \multicolumn{2}{l}{ Table-III: Association of gender to the grades of inflammation. } \\
\hline
\end{tabular}

\section{DISCUSSION}

Laparoscopic cholecystectomy is globally an acceptable treatment option for symptomatic gall bladder disease. In west, open cholecystectomy is now only the last resort for few indications only. However, in Pakistan, open cholecystectomy is still in practice for symptomatic gall bladder disease due to multiple reasons including lack of laparoscopic training, financial restraints in private hospital setups, lack of laparoscopy facility in majority of public secondary care hospitals and patient's preference for conventional surgical method $^{12}$. Multiple factors have contributed to the complications following laparoscopic cholecystectomy. Conversion of laparoscopic procedure to open cholecystectomy is a dreadful but common complication in morbidly obese patients with chronic cholecystitis and a thick wall of gall bladder, and in patients having multiple co-morbid health conditions ${ }^{13}$. Moreover, It has been established that LC performed by experienced surgeons is the safest and most effective management option for acute cholecystitis. Hot cholecystectomy has been proved to be more beneficial if performed within 4 hours of initiation of symptoms resulting in to shorter hospital stay and decreased conversion rate to open cholecystectomy ${ }^{14-15}$. Interestingly, data from the National Hospital Discharge Survey from 2000 to 2005 revealed that the patients who underwent conversion from LC to open cholecystectomy still had lesser morbidity and mortality as compared to those patients
We have shared our tertiary care experience of laparoscopic cholecystectomy in patients with symptomatic gall bladder disease. Out of 330 operated cases, $39 \%$ had acute inflammation while $61 \%$ had chronic inflammation of the gall bladder. The ratio of acute to chronic inflammation is somewhat higher then reported in the similar studies. Cox et al, reported $23 \%$ of the laparoscopically operated patients had acute inflammation, $28 \%$ had chronic inflammation of gall bladder, and $48.6 \%$ patients had symptomatic gall stones but no inflammation of gall bladder ${ }^{17}$. The overall conversion rate reported in our study for both acute and chronically inflamed gallbladders was lesser i.e. $4.5 \%$ as compared to other similar studies. Cox et al, reported 33.7\% and $21.7 \%$ conversion rates in acute and chronic inflammation of gall bladder respectively ${ }^{17}$. Lo et al, reported an overall conversion rate of $11 \%$ and Eldar et al, documented a conversion rate of $4.5 \%$ for uncomplicated acute cholecystitis'8-19. In our study, the commonest cause for conversion from laparoscopic cholecystectomy to open cholecystectomy in acute inflammation of gall bladder was Empyema of gall bladder $(1.2 \%)$ compared to $28.5 \%$ conversion rate reported by Eldar et al, for empyema of gall bladder and 28.5\% conversion rate for hydrops in acutely inflamed gall bladders per-operatively found during laparoscopic cholecystectomy ${ }^{19}$. The commonest cause of conversion in chronic inflammation was CBD Stone $(1.8 \%)$ followed by biliary pancreatitis $(0.9 \%)$. Post-operative complications like pancreatitis $(0.9 \%)$, bile leak $(0.3 \%)$, sep- 
sis $(0.6 \%)$, deep venous thrombosis $(0.3 \%)$, ileus $(0.3 \%)$ and Atelectasis $(0.3 \%)$ were common in higher grades of inflammation of gall bladder i.e. grade 3-5. Post-op complications like common hepatic duct injury $(0.6 \%)$, surgical site infection $(0.9 \%)$ and pneumonia $(0.3 \%)$ were more commonly documented in lower per-operative grades of gall bladder inflammation i.e. grade 12 of gall bladder inflammation.

The correlation of both gender i.e. male and female with the grades of inflammation revealed that in both genders, grade- 2 inflammation of the gall bladder was the commonest i.e. $61.3 \%$ in males and $45.2 \%$ in females and the results were statistically significant ( $p$-value <0.05). As far as the operative findings were concerned, dense adhesions (33.3\%) were most commonly found in grade- 3 inflammation of gall bladder and thin adhesions (66.3\%) were commonest in gall bladders with grade- 2 inflammation per-operatively. On pre-operative evaluation by ultrasonography $\mathrm{Ab}$ domen, the commonest reported finding in our study sample was multiple gall stones in $82.4 \%$ patients.

\section{CONCLUSION}

LC is the gold standard treatment for symptomatic gall stones. LC is the gold standard treatment for symptomatic gall stones, Moreover, it is a safe option in acute and chronic inflammation of gall bladder if performed by an experienced laparoscopic surgeon. Hospital should consider the patient and treating physicians factors, medical facility and demographic factors when making a decision with respect to the timing of operation.

\section{CONFLICT OF INTEREST}

This study has no conflict of interest to be declared by any author.

\section{REFERENCES}

1. Sugrue M, Sahebally SM, Ansaloni L, Zielinski MD. Grading operative findings at laparoscopic cholecystectomy - a new scoring system. World J Emerg Surg 2015; 10(2): 14-18.

2. Acar T, Kamer E, Acar N, Atahan K, Bag H, Haciyanlı M, et al. Laparoscopic cholecystectomy in the treatment of acute cholecystitis: comparison of results between early and late cholecystectomy. Pan Afr Med J 2017; 26(1): 49-52.
3. Terho PM, Leppäniemi AK, Mentula PJ. Laparoscopic cholecystectomy for acute calculous cholecystitis: a retrospective study assessing risk factors for conversion and complications. World J Emerg Surg 2016; 11(1): 54-60.

4. Ukkonen M, Kivivuori A, Rantanen T, Paajanen H. Emergency Abdominal Operations in the Elderly: A Multivariate Regression Analysis of 430 Consecutive Patients with Acute Abdomen. World J Surg 2015; 39(12): 2854-61.

5. Passos MA, Portari-Filho PE. Antibiotic prophylaxis in laparoscopic cholecistectomy: is it worth doing. Arq Bras Cir Dig 2016; 29(3): 170-72.

6. Radunovic M, Lazovic R, Popovic N, Magdelinic M, Bulajic M, Radunovic L, et al. Complications of laparoscopic cholecystectomy: our experience from a retrospective analysis. Maced J Med Sci 2016; 4(4): 641-46.

7. Kreimer F, Cunha DJ, Ferreira CC, Rodrigues TM, Fulco LG, Godoy ES. Comparative analysis of preoperative ultrasonography reports with intraoperative surgical findings in cholelithiasis. Arq Bras Cir Dig 2016; 29(1): 26-29.

8. Taki-Eldin A, Badawy AE. Outcome of laparoscopic cholecystectomy in patients with gallstone disease at a secondary level care hospital. Arq Bras Cir Dig 2018; 31(1): e1347-52.

9. Borges MC, Takeuti TD, Terra GA, Ribeiro BM, Rodrigues-Júnior V, Crema E. Comparative analysis of immunological profiles in women undergoing conventional and single-port laparoscopic cholecystectomy. Arq Bras Cir Dig 2016; 29(3): 164-69.

10. Gupta V, Jain G. Safe laparoscopic cholecystectomy: Adoption of universal culture of safety in cholecystectomy. World J Gastrointest Surg 2019; 11(2): 62-84.

11. Mou D, Tesfasilassie T, Hirji S, Ashley SW. Advances in the management of acute cholecystitis. Ann Gastroenterol Surg 2019; 3(3): 247-53.

12. Mirza MR, Wasty WH, Habib L, Jaleel F, Saria MS, Sarwar M. An Audit of Cholecystectomy. Pak J Surg 2007; 23(2): 104-108.

13. Shea JA, Berlin JA, Backwich DR. Indications for and outcomes of laparoscopic cholecystectomy; a comparision of pre and post laproscopic eras. Ann Surg 1998; 227(1): 343-50.

14. Lai PB, Kwong KH, Leung KL, Kwok SP, Chan AC, Chung SC, et al. Randomized trial of early versus delayed laparoscopic cholecystectomy for acute cholecystitis. Br J Surg 1998; 85(1): 764-67.

15. Singhal T, Balakrishnan S, Grandy-Smith S, Hunt J, Asante M. Gallstones: best served hot. J Soc Laparoend 2006; 10(3): 332-35.

16. Csikesz NG, Tseng JF, Shah SA. Trends in surgical management for acute cholecystitis. Surg 2008; 144(2): 283-89.

17. Cox MR, Wilson TG, Luck AJ, Jeans PL, Padbury RT, Toouli J. Laparoscopic cholecystectomy for acute inflammation of the gallbladder. Ann Surg 1993; 218(5): 630-34.

18. Lo CM, Fan ST, Liu CL, Lai EC, Wong J. Early decision for conversion of laparoscopic to open cholecystectomy for treatment of acute cholecystitis. Am J Surg 1997; 173(6): 513-17.

19. Eldar S, Sabo E, Nash E, Abrahamson J, Matter I. Laparoscopic cholecystectomy for acute cholecystitis: prospective trial. World J Surg 1997; 21(5): 540-45. 